\title{
Screening Mentally Retarded Children for Inborn Errors of Metabolism
}

\author{
Naveen K Shreevastava, ${ }^{1}$ Arti S Pandey ${ }^{1}$ \\ 'Department of Biochemistry, Kathmandu Medical College, Kathmandu, Nepal.
}

\section{ABSTRACT}

\begin{abstract}
Background: Most inborn errors of metabolism result in mental retardation and death due to accumulation of abnormal metabolites in the tissues. The presence of abnormal metabolites in the urine of mentally retarded individuals has been used worldwide for detection of inborn errors of metabolism. The purpose of the study is to determine the prevalence of inborn error of metabolism in mentally retarded children.

Methods: Random urine samples were collected from mentally retarded children at two institutes in Kathmandu, and also from 60 normal children from Duwakot, Nepal after obtaining consent from their parents. Urine was then tested for the presence of amino acids, keto-acids, mucopolysaccharides, fructose, glucose and protein using simple qualitative color reactions in the laboratory.

Results: The tests detected eight cases of Phenylketonuria, which turned out to be false positive on paper chromatography. Three cases of presence of ketone bodies (acetoacetate), ten cases of $\alpha$-ketoaciduria, two cases of mucopolysaccharidosis and twelve cases of fructosuria amongst the sixty-two urine samples were also found.

Conclusions: Certain aminoacidurias, ketoacidurias and mucopolysaccharidoses might be present in the Nepalese population. Within consideration of errors, the samples tested positive should be evaluated by a higher end method to confirm the utility of these simple and cheap chemical tests.
\end{abstract}

Keywords: Inborn errors of metabolism; ketoaciduria; mental retardation; mucopolysaccharidosis; phenylketonuria

\section{INTRODUCTION}

Inborn errors of metabolism (IEMs) are a group of genetic disorders that result in a structurally or functionally altered protein, resulting in a block in a metabolic pathway. Several hundred hereditary metabolic disturbances are known, many of which correspond to grave illnesses that frequently evolve to death or cause mental deficiency. ${ }^{1}$

Several groups of IEMs typically present with acute life threatening symptoms of acute encephalopathy and epilepsy as a result of toxic effects of accumulating metabolites on the central nervous system. ${ }^{2}$ Studies in Nepal have shown a prevalence of neonatal encephalopathy of 6.1 per thousand births ${ }^{3}$ while a community survey showed the prevalence of epilepsy to be 7 per 1000 population. ${ }^{4}$ IEMs in Nepal have been reported as cases in literature and their prevalence in the Nepalese population is unknown.

This study was undertaken to initiate an investigation regarding the existence of IEMs in the Nepalese popu- lation beginning with mentally retarded children. Noninvasive, simple and inexpensive chemical methods of screening urine for abnormal metabolites were used. ${ }^{5}$

\section{METHODS}

Ethical clearance for carrying out the IEM urinalysis was obtained from Nepal Health Research Council, Ministry of Health \& Population, Kathmandu and samples were obtained only with consent of parents or guardians. Random urine samples were obtained from a total of 62 children from the Association for the Welfare of Mentally Retarded (AWMR) in Sinamangal and Navajyoti Centre (School for Mentally Handicapped Children), Baluwatar, both situated in Kathmandu, Nepal over a period of eight months (Jan 2012 - August 2012).A subpopulation of children with mental retardation was selected at the two institutions. This group of children had a higher probability of the presence of IEM. The volume of urine collected was variable and was sufficient to perform the tests at least once. The volume of urine needed to perform each test was calculated from the urinary cre- 
atinine concentration (Table 1). Age, sex and ethnicity matched urine samples from 60 children visiting Kathmandu Medical College, Duwakot were also tested after obtaining consent from their parents (Table 2). Children with only physical disabilities and no mental retardation were excluded.

Urine samples were kept and transported on ice and frozen immediately on arrival at the Biochemistry Laboratory at Kathmandu Medical College (KMC) Basic Sciences, Duwakot, Bhaktapur. Data was collected on age, gender, caste, available diagnosis, sensory deficits, epilepsy with the help of the staff of the respective institutes.

Glucose, $\mathrm{pH}$ and protein were tested using CybowTM dip sticks from DFI. Simple chemical tests were performed on the urine samples to test for various groups of inborn errors (Table 1.). ${ }^{5}$ All samples were examined through paper chromatography on 4 MM chromatography paper using n-butanol: glacial acetic acid: water the ratio of $12: 3: 5$, followed by staining with ninhydrin reagent.
Urinary creatinine was determined using the alkaline picrate method.

\section{RESULTS}

Of the 71 participating children, only 62 urine samples were of sufficient volume for examination for all of the above mentioned tests. The demographic data of cases and controls was as shown in Table 2.

The average age of the participants was $13.69 \pm 4.34$ years. Seven of the children had vision deficit and one had hearing deficit. Information of degree of retardation was available only for 51 participants of whom six were classified as mild, 34 moderate and 11 severely retarded. There was one participant with cerebral palsy.

Urinary creatinine was measured using the picric acid method in order to assess the concentration in urine. The volume of urine used for the tests was then adjusted to a fixed equivalent of creatinine as shown in Table 1.

\section{Table 1. Urine metabolites tested and their associated disorders.}

\begin{tabular}{|c|c|c|c|c|c|}
\hline Metabolites & Tests & Associated IEMs & $\begin{array}{l}\text { Creatinine } \\
\text { equivalent } \\
(\mu \mathrm{g})\end{array}$ & $\begin{array}{l}\text { Positive } \\
\text { cases }\end{array}$ & False positive \\
\hline $\begin{array}{ll}\text { Ketoacids } & \text { (Phenylpy- } \\
\text { ruvate, } & \text { phenyllac- } \\
\text { tate) } & \end{array}$ & Ferric chloride & $\begin{array}{l}\text { Specific for Phenylketon- } \\
\text { uria, } \\
\text { Also positive in Tyrosin- } \\
\text { osis, Tyrosyluria, Maple } \\
\text { syrup urine disease, Hy- } \\
\text { perglycinemia }\end{array}$ & 500 & 8 & $\begin{array}{l}\text { Salicylate, chl } \\
\text { orpromazine,p } \\
\text { roclorperazine } \\
\text {,bilirubin }\end{array}$ \\
\hline \multirow[t]{2}{*}{ Muco-polysachharides } & $\begin{array}{l}\text { a. Cetyltrimethyl } \\
\text { ammoniumbromide } \\
\text { (CTAB) }\end{array}$ & Mucopolysachharidoses & 500 & 15 & $\begin{array}{l}\text { Reducing } \\
\text { substances, } \\
\text { certain } \\
\text { aminoacidurias }\end{array}$ \\
\hline & b. Toluidine blue & Mucopolysachharidoses & 50 & 18 & \\
\hline $\begin{array}{l}\text { a-Ketoacids (Pyru- } \\
\text { vate, a ketoglutarate } \\
\text {,ketoisocaproate, keto } \\
\text { methylvalerate) }\end{array}$ & $\begin{array}{l}\text { Dinitrophenyl } \\
\text { hydrazine (DNPH) }\end{array}$ & $\begin{array}{l}\text { Phenylketonuria(PKU), } \\
\text { Maple syrup urine } \\
\text { disease(MSUD), } \\
\text { Tyrosinosis, Tyrosyluria, }\end{array}$ & 500 & 10 & $\begin{array}{l}\text { Acetone } \\
\text { Butanone }\end{array}$ \\
\hline Fructose & Seliwanoff's & Fructosuria & 125 & 12 & Overheating \\
\hline \multirow[t]{2}{*}{ Amino acids } & a. Ninhydrin & Aminoacidurias & 75 & 13 & $\begin{array}{l}\text { Ammonium } \\
\text { salts, } \\
\text { concentrated } \\
\text { urine }\end{array}$ \\
\hline & $\begin{array}{l}\text { b. Paper chroma- } \\
\text { tography }\end{array}$ & Specific aminoacidurias & 4 & 5 & \\
\hline
\end{tabular}




\begin{tabular}{|c|c|c|}
\hline & Control (60) & Case (62) \\
\hline Mean Age(yrs) & $14.2 \pm 5.20$ & $13.69 \pm 4.34$ \\
\hline Females(\%) & $22(36.66)$ & 19 (30.64\%) \\
\hline Caste & $\begin{array}{l}\text { Newar }(73 \%), \text { In- } \\
\text { do-Aryan(20\%), } \\
\text { Mongolian (2\%) } \\
\text { \& Others }(5 \%)\end{array}$ & $\begin{array}{l}\text { Indo-Ary- } \\
\text { an }(64.51 \%) \text {, } \\
\text { Newar(25.8\%), } \\
\text { Mongolian (3.22\%), } \\
\text { Tharus }(1.61 \%) \& \\
\text { Others }(4.83 \%)\end{array}$ \\
\hline $\begin{array}{l}\text { Mean Urinary } \\
\text { creatinine } \\
(\mathrm{mg} / \mathrm{dl})\end{array}$ & $36.33 \pm 25.37$ & $42.94 \pm 39.89$ \\
\hline
\end{tabular}

The ferric chloride test was considered positive for PKU for eight of the samples which turned greenish. The ferric chloride test color obtained seemed to be a function of how concentrated the urine was, as determined by the urinary creatinine. An immediate brown colour with ferric chloride is obtained with 3-hydroxy anthranilic acid, indicative of pyridoxine dependent disorders. ${ }^{7} \mathrm{~A}$ red brown color indicates acetoacetic acid, but could also be formed by reaction of $\mathrm{FeCl}_{3}$ with common drugs such as salicylates. Accordingly, eight of the participants were probable cases of phenylketonuria and three of ketonuria (acetoacetate).

Phenylalanine (Phe), Leucine (Leu) and Isoleucine (Ile) were added to normal urine to make standards for comparison of migration of amino acids during paper
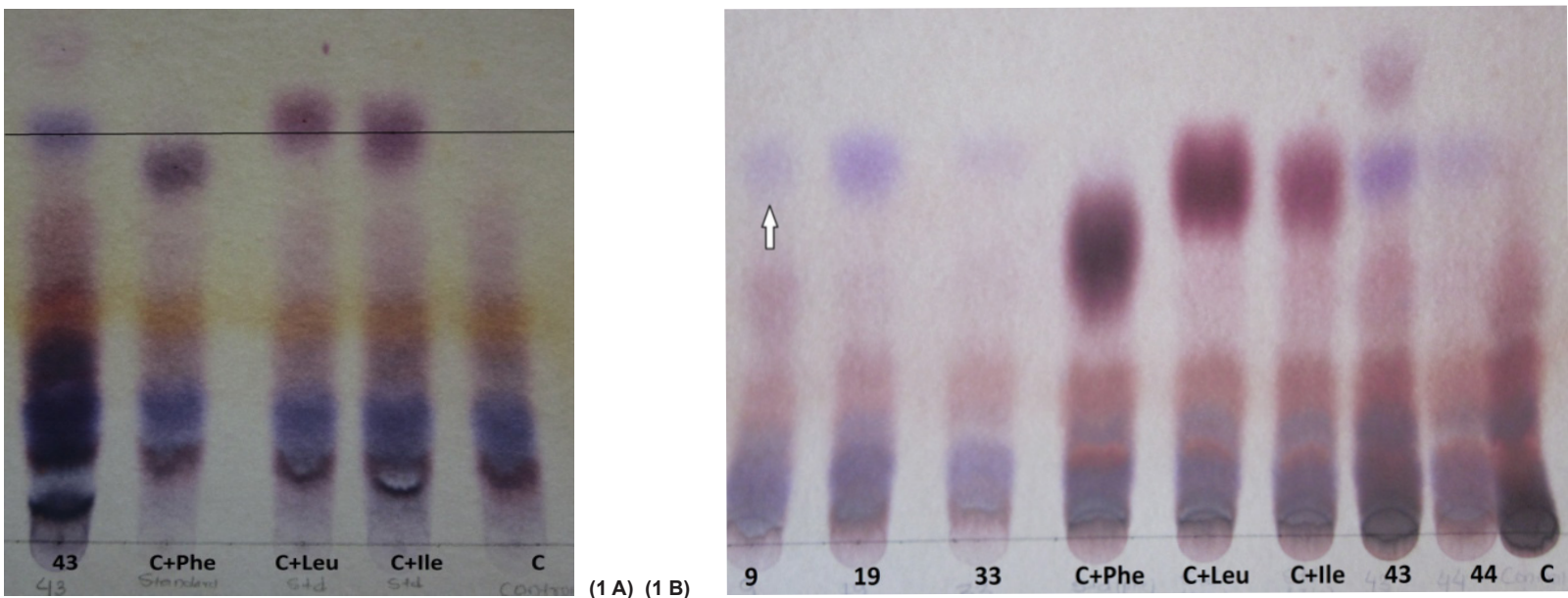

Figure 1. 1A - Paper chromatography of urine samples testing positive for Phe, The chromatography was run for 9 hours with one of the test samples (1B, extreme left lane) with control urine mixed with Phe, Leu and Ile respectively. The black line at the top in $1 \mathrm{~B}$ passes through the centers of the band for test and lle.

chromatography( Figure 1.). In order to resolve whether the bands in the test samples corresponded with Phe, Leu or Ile, chromatograms were run with one of the test samples for nine hours (Figure 1B.), and the band originally thought to be that of Phe was found to comigrate with lle. Urine samples of controls did not show any characteristic band on the chromatograms (figure 1A).

The DNPH test indicates the presence of ketoacids and considered positive if turbidity or precipitation is seen on addition of the reagent. Ten of 59 available urine samples showed some precipitation, an example of which is shown in comparison to a control in Figure 2.

Fifteen of the samples showed a positive CTAB test, which is the appearance of a flocculent precipitate and 18 showed a purple ring with Toluidine blue.

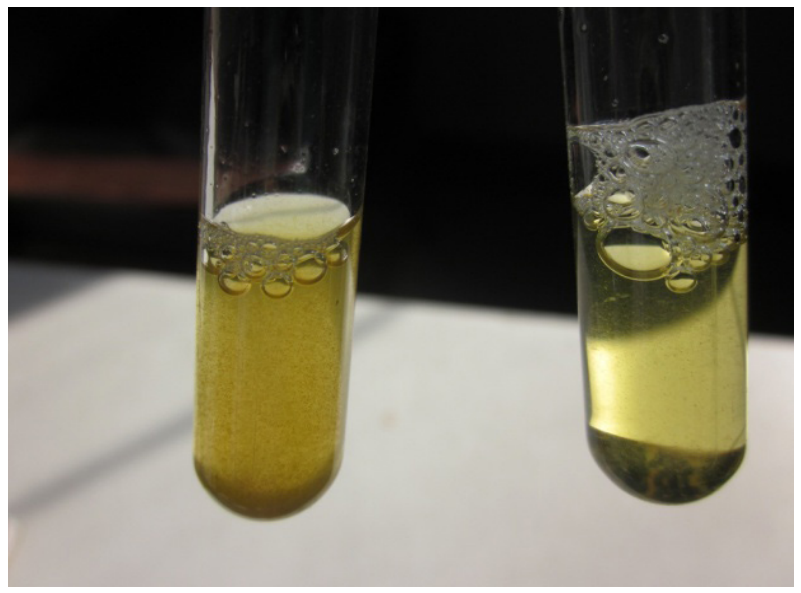

Figure 2. The DNPH test showing precipitation in the sample (left) taken as positive compared to the one (right) taken as negative. 
A positive toluidine blue test is indicated if the blue stain does not wash out in the acetic acid solution due to an excess of chondroitin sulfate. According to Buist, ${ }^{5}$ when excess mucopolysaccharides are present, the dried urine stains a reddish purple color, while the background remains pale blue (Figure 3). A reddish purple color could be discerned only in one sample (Figure $3(T)$ ) although a purple stain could be observed in several of them. On considering the urinary creatinine concentration, CTAB and toluidine blue test together, two cases could be isolated which had a urinary creatinine of $<30 \mathrm{mg} / \mathrm{dl}$, but were positive for both the CTAB and toluidine blue tests. Both children were males, 11 and 17 years of age, had moderate mental retardation and did not show any other tests positive.

Twelve test samples were positive and all control samples

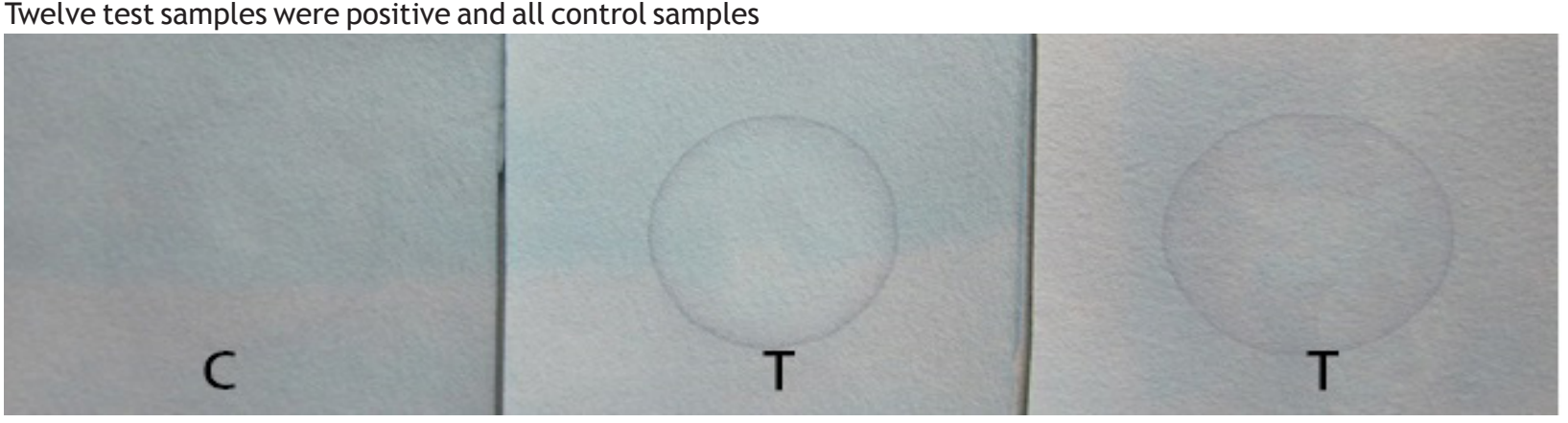

Figure 3. The toluidine blue test for mucopolysaccharidosis. Examples of urine spot samples that did not wash out with acetic acid are shown in the middle and right comparison with a control on extreme left.

\section{DISCUSSION}

The people in Nepal can be broadly classified according to their origin as Indo-Aryans, Mongolians and the aborigines called Tharus. ${ }^{6,7}$ There is high prevalence of marriages within a caste and also of consanguinity amongst some tribes of Nepal. The prevalence of genetic disease including metabolic disorders in Nepal is not known. Many cases of inborn errors, e.g., Glucose-6-Phosphate dehydrogenase deficiency, ${ }^{8}$ alkpatonuria, ${ }^{9}$ carnitine deficiency, ${ }^{10}$ Wilson's disease, ${ }^{11}$ Hunter's syndrome, ${ }^{12}$ Marquio's syndrome ${ }^{13}$ and muscular dystrophy ${ }^{14}$ have been reported from Nepal. In order to screen for the existence of IEMs, it is rational to start with a high risk population using simple, cheap and non invasive tests. The clinical information on the children participating in this study, where available, was a working diagnosis which had not been confirmed through any laboratory tests. Most children had "mental retardation" as a diagnosis in their records at these institutions.

Although the ferric chloride test has low sensitivity and is highly prone to cross reactivity with interfering substances in the urine, it has been used successfully in preliminary mass screening programmes for phenylketonuria and in surveys of mental institutions. ${ }^{5}$ were negative for fructosuria. There was only one case of glycosuria accompanied by proteinuria. There were three cases which tested positive for protein: an eleven year old male who also tested positive for fructosuria and mucopolysaccharidosis, a 15 year old female also positive for glycosuria and an 11 years old male with fructosuria. All control urine samples were negative for glucose and protein.

A logistic regression of the presence of a positive test taken as the outcome, was performed with the degree of mental retardation as the dependent variable. The odds ratios for any of the IEM tests being positive with an increase in degree of retardation from mild to moderate to severe was statistically insignificant $(p=0.537$, mild to moderate and $p=0.407$, moderate to severe). 
present with nephrotic syndrome..$^{15,16}$ The positive cases of proteinuria in this study were also positive either for fructose or glucose, indicating kidney dysfunction that might be secondary to metabolic disease.

Two cases tested positive for mucopolysaccharidosis in our study. Confirmatory tests would require electrophoretic separation of plasma to confirm the presence of MPS, which was not done because of invasiveness of blood sample collection.

A major drawback in our study was lack of availability of clinical data on the children, so that the test findings could not be correlated with the clinical manifestations. On the other hand, the study was hence made double blinded, preventing bias that is introduced during tests that need to be discerned by the naked eye. Nevertheless, mucopolysaccharidosis and organic acidurias should be explored further in the Nepalese population using gaschromatography and tandem mass spectrophotometry. Although amino acidurias are absent, the detection of the amino acid co-migrating with lle also warrants further investigation.

Another factor to be taken into account is that many metabolic diseases such as organic acidemias and storage disorders are fatal. Most IEMs are autosomal recessive and manifest when both alleles are mutated. In a sample of children already past five years of age or having entered teenage, the probability of detection of an IEM is lower than that for newborns. A nationwide study targeting newborns and using higher end methods of detection like tandem mass spectroscopy is required

Given the cases of IEMs reported from Nepal, our study corroborates the need for establishing a protocol for diagnosis and management of IEMs. In the neonate, the early clinical features of acute metabolic disease are almost always non-specific: they include illness, lethargy, feeding problems, vomiting, abnormal breathing, hypotonia and seizures. Initial blood testing when an IEM is suspected should include complete blood count with differential, urinalysis, serum electrolytes, glucose, blood gases, ammonia and lactate studies. ${ }^{2}$ In a rapidly deteriorating baby, performing a quick urine test can guide the physician towards specific confirmatory tests for timely intervention. In a setting such as Nepal, a cheap urine test that can detect the presence of phenylketonuria or mucopolysaccharidosis is a better option than no test at all.

\section{CONCLUSIONS}

Urinary screening in newborns in Nepal can be performed with simple chemical tests. A clinical examination combined with these simple tests can help guide the clinicians towards specific disorders and diagnostic tests for their confirmation.

\section{ACKNOWLEDGEMENTS}

We are grateful to Sister Suma, Director, Navajyoti Centre School for the Mentally Handicapped Children and Mr. Rabindra KC, Director, AWMR, Sinamangal, for their cooperation and support in this study. We also thank the staff at these two institutes who helped us with sample and data collection.

\section{REFERENCES}

1. Goodman SI. Inherited metabolic disease in the newborn: approach to diagnosis and treatment. Adv Pediatr. 1986;33:197-223. [PubMed]

2. Burton BK. Inborn errors of metabolism in infancy: a guide to diagnosis. Pediatrics. 1998;102(6):e69. [PubMed]

3. Ellis M, Manandhar N, Manandhar DS, Costello AM de L. Risk factors for neonatal encephalopathy in Kathmandu, Nepal, a developing country: unmatched case-control study. BMJ. 2000;320(7244):1229-36. [PubMed]

4. LeeAC, Mullany LC, Tielsch JM, KhatrySK, Katz J, LeClerq $\mathrm{SC}$, et al. Risk factors for neonatal mortality due to birth Asphyxia in southern Nepal: a prospective, community based cohort study. Pediatrics. 2008;121(5):e1381-90. [PubMed]

5. Buist NR. Set of simple side-room urine tests for detection of inborn errors of metabolism. Br Med J. 1968;2:745-9. [PubMed]

6. Pandey AS. Metabolic disease in Nepal: a perspective. Kathmandu Univ Med J. 2010;8(31):333-40. [PubMed]

7. Sharma PR. Caste, social mobility and sansktritization: state and society in Nepal. Kathmandu:Himal Books;2004.

8. Matsuoka H, Jichun W, Hirai M, Yoshida S, Arai M, Ishii A, et al. Two cases of glucose-6-phosphate dehydrogenasedeficient Nepalese belonging to the G6PD Mediterraneantype, not India-Pakistan sub-type but MediterraneanMiddle East sub-type. J Hum Genet. 2003;48(5):275-7. [PubMed]

9. Das RN, Shetty K J, Dham SK. A man with pigmented skin, dark urine and arthritis: what is your diagnosis? Int J Rheum Dis. 2005;8:131-4.

10. Chandranipapongse W. Case presentation: a 23 month old Nepalese boy, Kathmandu, Nepal. At Prasong Toujinda Conference Room; 2007. Available from: URL: http:// 
www.ped.si.mahidol.ac.th/site data/mymaindata pedsi/999999/GrandRound/grandround2007/gr0132007.pdf

11. Sharma AK, Sitaula S, Thapa M, Shrestha GS, Gajurel BP, Oli KK. Kayser-Fleischer ring evaluation in Wilson's disease in a tertiary care center of Nepal. Journal of Chitwan Medical College. 2014;4(9):17-20.

12. Rayamajhi A, Pokharel PJ, Chapagain R, Rayamajhi AK. Mucopolysaccharidosis type II with inguinal hernia. J Nepal Health Res Counc. 2013 Sep;11(25):293-5. [PubMed]

13. Malla KK, Malla T, Basnet S, Rao KS, Tiwari PK, Ghosh A, et al. Morquio Syndrome in two siblings: a Case Report.J Nep Paedtr Soc. 2010;31(1):68-71. doi: 10.3126/jnps. v31i1.3541.

14. Pokharel RK, Brisco L, Mandal M, Agrawal JP, Dillon D, Vitale M, et al. Effect of sitting posture on development of scoliosis in duchenne muscular dystrophy cases. JNepal
Health Res Counc. 2014 May-August; 12(27):94-9. [PubMed]

15. Martens DH, Rake JP, Navis G, Fidler V, Van Dael CML, Smit PA. Renal function in glycogen storage disease type 1 , natural course, and renopreservative effects of ACE inhibition. Clin J Am Soc Nephrol. 2009;4(11):1741-6. [PubMed]

16. Taylor J, Thorner P, Geary DF, Baumal R, Balfe JW. Nephrotic syndrome and hypertension in two children with Hurler syndrome. J Pediatr. 1986 May;108(5 Pt 1):726-9. [PubMed] 